\title{
Innovations Related to Hydrology in Response to Climate Change - A Review
}

\author{
Kaufui V. Wong ${ }^{*}$ and Craig Lennon
}

Mechanical and Aerospace Engineering Dept., U. Miami, Coral Gables, FL, USA

\begin{abstract}
Water is one of the most valuable and necessary resources on this planet, and the demand rate is increasing greater than the supply rate. In response to rapidly growing water needs, we must become more efficient with our water usage.

As agriculture is one of the primary uses of potable water across the globe, increases in efficiency in this aspect can have substantial impact. Smarter management and planting strategies, only with more drought-resistant crops, can have a large impact upon plant yields.

One of the major untapped water resources in developing countries is untreated wastewater. The amount of wastewater collected in some of these countries can equal almost a third of their total water needs, yet less than half is treated. Africa, a fairly dry continent, only treats $1 \%$ of its wastewater. Wastewater treatment technology continues to advance, as pollutants are removed more efficiently, with less power demand from the treatment plants.
\end{abstract}

The most common plants today are activated sludge plants, but newer membrane bioreactors are demonstrating superior filtration and thus effectiveness at comparable costs.

Nanotechnology is an exciting new approach to wastewater treatment, as it is by far the most effective at cleansing water, and identifying pollutants. Currently, it is too expensive for widespread implementation. It could become feasible in the near future if the economies of scale begin to drive down the price.

\begin{abstract}
Groundwater is also a key resource in many arid developing countries, but care must be taken not to overuse it. Sufficient time must be taken to allow for aquifer recharge. In addition, the levels of nitrogen and sodium must be monitored to prevent a harmful buildup.

The most easily available implementation, which requires no capital cost, is simply policy change. Several countries in the region can be used as a model for smart wastewater management, as some have attained treatment rates of over $85 \%$.
\end{abstract}

Keywords: Groundwater, nanotechnology, water, wastewater.

\section{INTRODUCTION}

Water is becoming an ever more precious resource. Climate change only exacerbates what is already becoming an ever more pressing issue. Dry climates are faced with even more uncertainty and dwindling water supplies. In response to this rapidly increasing demand, careful water management is more crucial than ever.

Because it is difficult to find new sources of potable water, the challenge in fact reduces to effectively utilize current water sources. This can be accomplished in several different ways. Current applications, ranging from irrigation to personal hygiene, can be improved in order to minimize water use. Current water sources like ground water can be gathered and utilized more effectively, to maintain their viability as a renewable resource.

*Address correspondence to this author at the Mechanical and Aerospace Engineering Department, U. Miami, Coral Gables, FL, USA;

E-mail: kwong@miami.edu
In addition, it becomes ever more important to recycle the water we already use. Especially in developing, arid countries, wastewater is a largely untapped resource that will become absolutely crucial in the coming years. These countries are where it is absolutely crucial to maximize available water resources, as these countries expend as much as $90 \%$ of their water for irrigation, compared to $70 \%$ worldwide [1]. In these countries there is far less frivolous water consumption that could theoretically be cut back, just a pressing need for water. One such region, the Middle East and Northern Africa (MENA), collects the equivalent of $29.7 \%$ of their total water consumption as wastewater, showing that wastewater alone could make a massive impact on water resource sustainability [2].

The decentralization of wastewater treatment could also prove to be a boon to developing countries. This strategy helps to minimize the extra costs associated with the transport of water both to and from treatment facilities. Instead, smaller, localized plants can be used. 


\section{AGRICULTURAL DEMANDS}

With droughts becoming more and more prevalent, the agricultural community must find ways to thrive in drought conditions. In the case of maize production, farmers are combating drought through low and no tilling systems. This process eschews tilling the top layer of soil in favor of drilling narrow holes for the seeds to be planted. The main advantage of this method, especially when considering droughts, is the increased carbon dioxide retention of the soil. When the soil retains a higher concentration of carbon dioxide, the plants will use water more efficiently. Minimizing the water required to produce crops is one of the great challenges droughts provide, and enabling plants to utilize the precious available water more efficiently is a key improvement. Agriculture is often the primary consumer of a cultivated area's water resources, and as such even marginal gains in this field can have substantial effects. In addition, the process of conventional tilling often leaves the land vulnerable to erosion. No or low till farming has also the benefit of greatly reducing erosion, due to the better packed fields it creates.

No till farming is a relatively new development, but its core philosophy does not explicitly require advanced technology. It is quite probable that no till farming could have been implemented a long time ago. Tilling provides the advantages of killing weeds and creating primitive irrigation tracts, as well as organizing fields into orderly lines. No till farming simply requires a hole to be drilled in the ground, which is aided by modern technology, though the same end can be accomplished with simpler means. Modern herbicides also help to combat the weed problem, the most significant obstacle to no till farming, but weeds have always been a problem for farmers. This 'old' method of tilling that has been re-introduced in dry climes, is discussed here as an innovation in hydrology because it does produce favorable results by decreasing erosion. Erosion is a hydrological phenomenon when water flows through the earth, that needs to be curbed in many places or situations.

Many advances in farming technology have allowed farmers to vastly increase their raw yield over previous years. Yet despite the numerous technological discoveries, the yields of some crops, such as maize, are more sensitive to droughts than ever. Many other variables have been able to be controlled more effectively than in the past, especially when compared to drought. Although the absolute yield may be higher, even when considering drought conditions, the ability to control and overcome these conditions is still unsatisfactory. Another condition that exacerbates this condition is the increased crop density. From 1992 to 2012, crop density increased a staggering $25 \%$ [3]. Holding all other factors equal, drought stress has a far greater impact on the yield of more densely planted crops than those that are less dense, making crops more vulnerable to drought stress.

Though this data shows that the raw total yields may increase, the real problem is one of wasted potential. As droughts make it more difficult to grow crops in many regions, it is becoming increasingly important to maximize the available production. With drought stresses potentially accounting for a $30 \%$ loss in yield, it is crucial to find solutions for this specific problem.

\section{SOLAR DRIP IRRIGATION}

An innovative irrigation procedure has been engineered and carried out in Benin, Africa. Solar Electric Light Fund (SELF) is a corporation which supplies the resources to help spread the use of solar energy in areas around the world. SELF funded this solar drip irrigation method in Benin. It uses solar panels to power a very efficient drip irrigation system. It has been shown that drip irrigation is ideally suited to agriculture under dry conditions $[4,5]$.

SELF has also successfully implemented solar-powered community water wells, and the Solar Market Gardens for community workers, the later using solar drip irrigation [5]. This same innovative procedure in hydrology has been repeated with success in Haiti. SELF has made inroads into South America, with projects in Colombia. It is conceivable that the solar drip irrigation process would also be used there also.

\section{WASTEWATER REUSE}

One of the main areas that society may be able to improve upon in the face of drought is the reuse of wastewater. The proper treatment and recycling of previously used water can greatly expand the pool of available water to any society.

It can be clearly seen from Table $\mathbf{1}$ that massive amounts of wastewater are being squandered. The region being considered is the Middle East and North Africa (MENA). This region produces $13.2 \mathrm{~km}^{3}$ of wastewater annually while only treating $5.7 \mathrm{~km}^{3}$, or $43 \%$. Hence, $7.5 \mathrm{~km}^{3}$, or $7,500,000,000,000$ liters, are untreated. The total quantity of water utilized by the domestic and industrial sectors in this region is $44.4 \mathrm{~km}^{3}$ annually, so the untreated wastewater is significant when compared with the total water demands of the area [2].

\section{OPTIMAL RESOURCE MANAGEMENT}

Though water is becoming increasingly precious, our use of it continues to be sub-optimal. Using the wealth of information currently available, it is possible to more efficiently use current water resources without improved technology.

Currently, many sources of usable agricultural water, such as the Nile River Basin, are being polluted beyond healthy rates. The ability to notice these trends and enact policy on a larger scale is relatively new, thanks to increased availability and understanding of data. Properly treating wastewater before reintroducing it into potentially useful water is absolutely key in areas where water is already scarce. For example, raising and enforcing the standards for wastewater runoff into the El-Qalaa basin could reduce violations of total suspended solids by $50 \%$ and eliminate chemical oxygen demand violations [6]. Models such as the one featured in [6] are a hugely valuable tool for determining the root causes of pollution, as well as suggesting paths towards a solution that can be enacted through policy.

Jordan is an excellent example of a country with limited water resources attempting to maximize their potential through policy. The Wastewater Management Plan of 1998 outlines several key points: 
Table 1. Percedntage of collected wastewater treated. Data from [2].

\begin{tabular}{|c|c|}
\hline Country & $\begin{array}{c}\text { Wastewater Treatment } \\
\text { Rate (\% Collected) }\end{array}$ \\
\hline Algeria & 73 \\
\hline Bahrain & 100 \\
\hline Djibouti & 0 \\
\hline Egypt & 79 \\
\hline Iran & 4 \\
\hline Iraq & N/A \\
\hline Israel & 79 \\
\hline Jordan & 88 \\
\hline Kuwait & 87 \\
\hline Lebanon & 2 \\
\hline Libya & 7 \\
\hline Morocco & $6-8$ \\
\hline Oman & 13 \\
\hline Palestine & $34-54$ \\
\hline Qatar & N/A \\
\hline Saudi Arabia & 75 \\
\hline Syria & $57-67$ \\
\hline Tunisia & 79 \\
\hline UAE & 22 \\
\hline Yemen & 62 \\
\hline
\end{tabular}

-wastewater will not be disposed of, but is instead included in the water budget.

-planning of water reuse will take place on a basin-wide scale.

-use of recycled water will be encouraged.

-fees for wastewater treatment may be collected from those who utilize the water.

-crops irrigated with wastewater will be recorded and controlled [7].

These policies promote what should be considered an essential resource in recycled wastewater, while also making it more economically feasible. In addition, many developing countries are somewhat inefficient at reprocessing wastewater, so it is important to monitor crops irrigated with such water, to ensure that poorly filtered water does not negatively affect the environment or the local population.
These policies have contributed to Jordan treating $88 \%$ of its wastewater [2]. If other MENA countries began to treat $88 \%$ of their wastewater, there would be an addition $5.9 \mathrm{~km}^{3}$ of processed wastewater available for use, which covers $13.3 \%$ of the region's total water demand [2].

The willingness of many farmers in these water scarce regions towards using wastewater could also benefit from policy decisions. For example, Tunisian farmers have the option of paying $0.02 \mathrm{US} \$ / \mathrm{m}^{3}$ for reclaimed water versus $0.08 \mathrm{US} \$ / \mathrm{m}^{3}$ for conventional water, yet the demand for reclaimed water remains low [2]. This is in part due to the unreliable quality of reclaimed water in the area, and the alternative of free untreated wastewater. This pricing only reflects the current state of the water, without an eye towards long-term water resources. An increase in the price of conventional water that reflected its future rarity is most likely in order. A combination of taxation and subsidies that shifted demand towards more sustainable sources of water would be ideal.

\section{NANOTECHNOLOGY}

The adaptation of nanotechnology towards water filtration and purification can greatly improve the efficiency and effectiveness of water treatment.

Nanoabsorbers provide a vastly increased absorption surface area over conventional absorbers such as activated carbon. This increased ratio of surface area to particle volume allows for both a higher rate of absorption and a higher absorption capacity per unit volume. Nanoabsorbers have the ability to remove both organic and metallic contaminates. Their small size also allows them to diffuse rapidly, as the intraparticle distance required to effectively diffuse is much smaller than that of a larger absorbent.

Carbon nanotubes (CNTs) are one of the most effective options currently available, though the cost prohibits wider adaptation. Their primary use today is to filter out particles that cannot be removed using standard methods, such as antibiotics and polar aromatics [8]. Graphite oxide nanosheets may be produced fairly cheaply, and are therefore an interesting potential absorbent.

Metals can be absorbed through the use of metal oxide nanomaterials, such as nanomagnetite. Nanomagnetite's superparamagnetic properties allow it to easily separate from water when in the presence of even a weak magnetic field.

Nanotechnology has also excellent results when utilized as a membrane. This method allows for a low energy, low cost filtration system with excellent efficiency. This low energy approach is especially necessary in many of the areas hit hardest by drought. The African continent is particularly affected by drought, due to a comparative lack of natural water and sub par infrastructure. Yet despite this, only $1 \%$ of the wastewater generated in Africa is treated [9]. A filtration system with low energy demands would be particularly helpful in this sort of environment. Membranes also allow the process of filtration to be largely automated, as they passively filter water. This method also permits a variety of water sources to be treated in addition to wastewater, such as 
Table 2. Percentage reduction of total suspended soils (tss), chemical oxygen demand (cod) and total nitrogen (tn). data from [10, 11].

\begin{tabular}{|c|c|c|c|}
\hline Treatment Type & \% Reduction & COD & TN \\
\hline \hline Activated Sludge & TSS & 92 & 32 \\
\hline Trickling Filter Beds & 97 & 41 & 62 \\
\hline Lagooning & 53 & 38 & 75 \\
\hline Constructed Wetlands & 86 & 92 & \\
\hline AnMBR & & $>90$ & 72 \\
\hline
\end{tabular}

seawater. Membranes are subjected to fouling and blockage, especially when considering nano-channels, so care must be taken to reduce the harm of these obstacles. There are currently three main varieties of membranes utilizing nano technology, the carbon nanotube, the biomimetic membrane, and thin film nanocomposite membranes.

Nanotechnology use has also proven adept in sensing and disinfecting water. Because contaminants are often still harmful at extremely low concentrations, swiftly detecting and inactivating them is crucial for potable water. Quantum dots are extremely effective dye markers owing to their wide absorption bands and narrow emission spectrum.

Traditional disinfectants, such as chlorine, often leave behind harmful byproducts. Nanomaterials have the potential to effectively disinfect water without leaving behind byproducts that are toxic to humans. These disinfectants work by releasing metal ions that disrupt the integrity of the membranes of various microorganisms on contact. Nano-Ag is particularly effective because the various components of DNA are attracted to $\mathrm{Ag}^{+}$. These microorganisms can also be made inactive when hit with a short electrical pulse if trapped in a CNT membrane.

The main issue of nanotechnologies is that of cost. Until the scale of production is greatly increased, the price will remain prohibitively expensive. However, compromises in quality can be made. Using fullerene soot instead of pure $\mathrm{C}_{60}$ in aminofullerene photocatalysts reduces the price by $90 \%$ while hurting the effectiveness by only $10 \%$ [8]. Such sacrifices must be considered when thinking of implementation in impoverished areas of the world.

\section{CONVENTIONAL WASTEWATER TREATMENT}

The most common variety of wastewater treatment plant (WWTP) is the activated sludge (AS) method. Bacteria are introduced into the wastewater to create a floc with the pollutants. This floc, the "sludge", can be filtered out far more easily than untreated pollutants. This system is widely implemented throughout the world due to its low energy demands and low capital cost. However, it is not a standalone process, as wastewater is not immediately potable without several additional treatments.
Table 2 shows the effectiveness of activated sludge as compared to several other widely used methods. It differs from the latter three methods in that they are primarily passive treatment, whereas activated sludge treatment requires more active treatment, and thus has higher operational costs.

In the case of Free Water Surface (FWS) constructed wetlands versus a traditional activated sludge plant, the initial development costs for the FWS plant were found to be roughly eight fold higher than that of the traditional plant. This was offset by the lower operational costs of the FWS plant, which were about eight fold lower than its counterpart. It was found that the lower operational costs would allow the FWS plant to equal the costs of the activated sludge plant after three years of operation [12].

\section{MEMBRANE BIOREACTORS (MBR)}

MBRs are an effective treatment option with a wide variety of uses. They can be used to treat waste from potentially dangerous sources ranging from petrochemical waste [13] to pharmaceutical waste [14]. There are a wide variety of MBRs with many different filters, pumps and chemical treatments. Some of the ways they vary include membrane pore size, membrane configuration (vertical or horizontal), membrane classification (microfiltration or ultrafiltration), membrane material, fiber density and size, and the type of air scouring used. These plants currently use a comparable amount of energy to an activated sludge plant, of about 3 $\mathrm{kWh} \mathrm{m}^{-3}$. Much of the energy used in the membrane bioreactor plants is devoted towards the air blowers necessary to prevent fouling and concentration polarization known as the air scouring. These blowers are often found to use over $60 \%$ of the total energy used in the reactor [15]. Whereas these reactors do not yet provide an energy advantage over traditional methods, they do provide significantly cleaner water. Water from activated sludge plants must undergo further sand and ultra-violet UV filtration before it is acceptable to be used in irritation, while the membrane bioreactor provides water that is instantly usable.

It can also be helpful to combine AS treatment techniques with an MBR, by way of pre-treating the effluent. To test this theory, four varieties of MBR were tested with both 
Table 3. Percentage reduction of biological oxygen demand (BOD), chemical oxygen demand (cod), ammonia-nitrogen \& turbidity. data calculated from [16].

\begin{tabular}{|c|c|c|c|c|}
\hline & MBR Type & & & Kubota \\
\hline \% Removed & US Filter & 97.3 & 96.8 & Mitsubishi \\
\hline \hline Ammonia-nitrogen & 98.9 & $>99$ & $>99$ & $>99.9$ \\
\hline BOD & 99 & 96.2 & 96.4 & 95.2 \\
\hline COD & 95.8 & & & .06 \\
\hline Additional Water Quality Measure & & .08 & .06 & .07 \\
\hline Turbidity (NTU) & & & & \\
\hline
\end{tabular}

Table 4. g/ml of biological oxygen demand (BOD), chemical oxygen demand (COD), ammonia-nitrogen and total suspended solids (TSS) in inflow streams. Data calculated from [16].

\begin{tabular}{|c|c|c|c|}
\hline & Raw Wastewater & Advanced Primary Effluent & Reduction \\
\hline Ammonia-nitrogen $(\mathrm{g} / \mathrm{ml})$ & $\mathbf{2 6 . 7}$ & $\mathbf{2 6 . 1}$ & $\mathbf{2 . 2 \%}$ \\
\hline \hline BOD $(\mathrm{g} / \mathrm{ml})$ & 249.3 & 39.4 & $84.2 \%$ \\
\hline COD $(\mathrm{g} / \mathrm{ml})$ & 200 & 106 & $47.0 \%$ \\
\hline TSS $(\mathrm{g} / \mathrm{ml})$ & 484 & 224 & $53.7 \%$ \\
\hline
\end{tabular}

raw wastewater and advanced primary effluent (pre-treated wastewater).

In Table 3, it is shown that all four varieties of MBR were incredibly effective using raw wastewater as feed water, removing almost all pollutants present. Standards for turbidity, which measure similar to that of TSS, generally require values of less than 1.0 for drinking water, which all four easily meet.

The amount of various pollutants in both the raw wastewater and the advanced primary effluent and the two candidates to be fed into the MBR are shown in Table 4. The advanced treatment clearly aids in the process, as it does a significant amount of treatment on its own. The raw amount of ammonia-nitrogen, Biological Oxygen Demand (BOD), Chemical Oxygen Demand (COD), and Total Soluble Solids (TSSs) are very similar whether raw wastewater or advanced primary effluent is used. The difference concerns the operation of the reactor. When pre-treatment is used, less primary air needs to be used during operation, allowing overall energy needs to be drastically decreased, as the blowers consume more energy than any other component. The danger from using pre-treated water comes in the form of increased fouling, as the sludge can clog the narrow membrane. This problem is especially prevalent at high flux values, and requires more frequent cleaning.

A popular variety is the Anaerobic Membrane Bioreactor (AnMBR). These reactors are able to effectively process wastewater at a high rate, with minimal effect from varying hydraulic retention time (HRT). They can also tolerate significantly higher solid retention times (SRT) in the reactors [11]. The anaerobic treatment, by its nature, offers increased ability to eliminate biological pollutants.

\section{BIOFILTERS}

Biofilters are an incredibly promising field for developing countries, owing to their low operational and start-up costs, and variable size. Biofilters can be implemented in a variety of ways, through green roofs, living walls, and constructed wetlands. All of these methods involve using living organisms to filter out pollutants from wastewater.

One interesting potential application of these systems is small-scale domestic filtration. A combination of these three methods can be used to create a very low cost filtration system for domestic use with almost no maintenance costs or energy requirements. It was found that this type of system results in over a $92 \%$ reduction in BOD and nitrogen content. A system that can process 50 gallons/day of wastewater can be constructed for less than $\$ 300$ [17]. The downside of this method is that a large percentage of the water can be lost to evapotranspiration during treatment. This concern is somewhat mitigated if this method is implemented in areas where wastewater goes untreated, as it results in a net positive.

\section{GROUNDWATER}

In addition to wastewater, groundwater is a key resource in drought prone areas. For example, in Syria with an arid 
Table 5. Percentage Reduction of Total Suspended Solids (TSS), Chemical Oxygen Demand (COD), Ammonium. Data from [19].

\begin{tabular}{|c|c|c|c|}
\hline \multicolumn{4}{|c|}{ Performance of AS and MBR Plants } \\
\hline Pollutant & Amount in Wastewater (mg/L) & MBR \% Removed & AS \% Removed \\
\hline \hline TSS & $64+-22$ & 99.9 & 60.9 \\
\hline COD & $58+-18$ & 99.0 & 94.5 \\
\hline Ammonium (mg*N/L) & $20.2+-1.7$ & 99.2 & 98.9 \\
\hline
\end{tabular}

climate, groundwater accounts for over $50 \%$ of the water used for irrigation $[18,19]$. However, many regions are overusing this precious resource. If enough time is not given for aquifer recharge, then these are no longer sustainable resources. In addition, the continued use of groundwater for irrigation causes nitrogen and salinization buildups within the soil. This practice results in $1-2 \%$ of global irrigated lands to become non-arable each year [20]. This can be combated through increased use of surface water in irrigation, which can freshen the groundwater sources. However, many areas reliant on groundwater do so because of insufficient surface water resources. In these cases, recycling wastewater again becomes key. Recycling and properly treating wastewater can counteract the salinization and nitrogen buildups in both soil and groundwater reservoirs.

The continuous reuse of groundwater without treatment serves as a positively reinforcing cycle in terms of salinization and nitrogen buildup. The water becomes increasingly salinized and gains a higher nitrogen concentration when used for irrigation before seeping back into the groundwater. This increases the equilibrium salinization and nitrogen content of the groundwater, before it is again raised by the next cycle of irrigation. In many cases, this high nitrogen content is not accounted for by farmers, who over fertilize their crops as a result.

\section{COMPARISON OF MEMBRANE BIOREACTORS AND ACTIVATED SLUDGE PLANTS}

A more direct comparison of the AS plants and the MBR plants shows that both are viable options.

In Table 5, the effectiveness of both systems is illustrated. Though the AS plant lags behind in TSS removal, it comes at a cheaper energy cost than an MBR plant, and as such can be supplemented with additional treatment. However, MBR plants are shown to be a one step treatment option. They require little supervision, and if blower costs can be brought down, have minimal power requirements. They remove all kinds of pollutants, and can work with a wide variety of effluent sources. The effluent of the MBR also lacked enzymes, which were present in the AS effluent, another advantage for the MBR [21]. Both systems show effective nitrification, which is key for fertilization.

\section{DISCUSSION AND CONCLUSION}

The objective of this review is to look at innovations that have occurred in hydrology owing to climate change. One of the most important immediate impacts of climate change is the frequency of droughts. Droughts affect agriculture, and hence create water-food nexus problems wherever they occur. Hence, the review has focused on hydrological processes associated with agriculture.

While both of the AS and MBR systems that have been discussed above, can be effective, they must be widely used to see a real benefit. Both options can be deployed on smaller scales and used in a decentralized fashion, which is key in spread- out, sparsely populated areas. This small scale is an advantage over methods such as lagooning and manufactured wetlands, which generally must be deployed in a larger scale to become cost effective.

Overall, carefully planned wastewater treatment can mean an enormous difference in places such as Africa, where only $1 \%$ of wastewater is treated. Through smart governmental policy encouraging the collection, treatment, and reuse of wastewater, along with increased treatment capacity can lead to substantial gains in making potable water a more sustainable resource.

\section{CONFLICT OF INTEREST}

The authors confirm that this article content has no conflict of interest.

\section{ACKNOWLEDGEMENTS}

Declared none.

\section{REFERENCES}

[1] United Nations Water, Statistics, 2014, http://www.unwater.org/statistics/en/ [Retrieved 7/21/14].

[2] Qadir M. Wastewater production, treatment, and irrigation in middle east and north africa. Irrig Drain Syst 2010; 24(1-2): 37.

[3] Lobell DB, Roberts MJ, Schlenker W, et al. Greater sensitivity to drought accompanies maize yield increase in the US midwest. Science 2014; 344(6183): 516-19.

[4] Eaton. Solar Energy brings Food, Water, and Light to West Africa: National Geographic March 2012. http://news.nationalgeographic.co/news/energy/2012/03/120314solar-drip-irrigation-in-benin-africa/. [Retrieved 3/28/14].

[5] SELF website. Benin Programs, http:/ http://self.org/benin-3//. [Retrieved 8/1/14].

[6] Fleifle A, Saavedra O, Yoshimura C, Elzeir M, Tawfik A. Optimization of integrated water quality management for agricultural efficiency and environmental conservation. Environ Sci Pollut Res Int 2014; 21(13): 8095-111. 
[7] Nazzal YK, Mansour M, Al Najjar M, McCornick PG. Wastewater reuse law and standards in the kingdom of Jordan. Ministry of Water and Irrigation, Amman 2000.

[8] Qu X, Brame J, Li Q, Alvarez PJ. Nanotechnology for a safe and sustainable water supply: Enabling integrated water treatment and reuse. Acc Chem Res 2013; 46(3): 834-43.

[9] WHO (World Health Organization), UNICEF (United Nations Children's Fund) and WSSCC (Water Supply and Sanitation Collaborative Council) Global water supply and sanitation assessment 2000 report. WHO/UNICEF, Geneva 2000.

[10] Camacho-muñoz D, Martín J, Santos JL, Aparicio I, Alonso E. Effectiveness of conventional and low-cost wastewater treatments in the removal of pharmaceutically active compounds. Water Air Soil Pollut 2012; 223(5): 2611-21.

[11] Ho J. Sung S. Anaerobic membrane bioreactor treatment of synthetic municipal wastewater at ambient temperature. Water Environ Res 2009; 81(9): 922-8.

[12] Mannino I, Franco D, Piccioni E, Favero L, Mattiuzzo E, Zanetto G. A cost-effectiveness analysis of seminatural wetlands and activated sludge wastewater-treatment systems. Environ Manag 2008; 41(1): 118-29.

[13] Llop A, Pocurull E, Borrull F. Evaluation of the removal of pollutants from petrochemical wastewater using A membrane bioreactor treatment plant. Water Air Soil Pollut 2009; 197(1-4): 349-59.

[14] dos Santos LMF, Lo Biundo G. Treatment of pharmaceutical industry process wastewater using the extractive membrane bioreactor. Environ Prog 1999; 18(1): 34.
[15] Skouterisl G, Arnot TC, Jraou M, Feki F, Sayadi S. Modeling energy consumption in membrane bioreactors for wastewater treatment in north africa. Water Environ Res 2014; 86(3): 232-44.

[16] DeCarolis J.F, Adham S. Performance investigation of membrane bioreactor systems during municipal wastewater reclamation. Water Environ Res 2007; 79(13): 2536-50.

[17] Cameron RD. Wastewater as a water resource design, and operation of an integrated biofilter wastewater treatment and reuse system. ProQuest Dissertations and Theses. The Pennsylvania State University 2012.

[18] JICA (Japan International Cooperation Agency). The study on water-resource development in Northern and Central Basins in the Syrian Arab Republic: final report. Nippon Koei: Tokyo 1997.

[19] Jumaa V, Naji M, Pala M. Review paper on optimizing soil water use in Syria. In: Van Dulmkwden N, Pala M, Studer C, Bieldes CL, Eds. Proceedings of workshop on efficient soil water use. Soil Water Use Consortium; 26-30 April 1998; Niamey, Niger. Amman: Jordan 1999.

[20] Zhou Y, Zwahlen, F, Wang Y, Li Y. Impact of climate change on irrigation requirements in terms of groundwater resources. Hydrogeol J 2010; 18(7): 1571-82.

[21] Cicek N, Franco JP, Suidan MT, Urbain V, Manem J. Characterization and comparison of a membrane bioreactor and a conventional activated-sludge system in the treatment of wastewater containing high-molecular-weight compounds. Water Environ Res 1999; 71(1): 64 .

(C) Wong and Lennon; Licensee Bentham Open.

This is an open access article licensed under the terms of the Creative Commons Attribution Non-Commercial License (http://creativecommons.org/licenses/by-nc/3.0/) which permits unrestricted, non-commercial use, distribution and reproduction in any medium, provided the work is properly cited. 